\section{On the "misguided" use of reaction-time differences: A discussion of Ratcliff and Hacker (1981)}

\section{ROBERT W. PROCTOR and K. VENKATA RAO Auburn University, Auburn, Alabama}

Ratcliff and Hacker (1981) have argued against models of matching-task phenomena that are based on the commonly obtained finding that "same" judgments are faster than "different" judgments (cf. Proctor, 1981; Taylor, 1976). Their argument relies primarily on two experiments that they report, in which subjects are "biased" against making rapid "same" judgments. In both experiments, a reversal of the usual relationship is obtained such that "different" judgments are faster than "same" judgments. Because of this outcome, Ratcliff and Hacker conclude that the "same-different" disparity "can be easily manipulated to produce any pattern of reaction time differences" (p. 303), and, as a consequence, "that models based on the same-different difference are misguided" (p. 303). The present comment considers Ratcliff and Hacker's arguments and concludes that their position is strongly overstated.

That reaction time is sensitive to criterion manipulations is a point on which no one would disagree (see Pachella, 1974, for an excellent discussion of the relationship between speed and accuracy). That the usual tendency toward faster "same" judgments could be manipulated by introducing a bias against making rapid "same" judgments would also surprise no one. Rather, the fundamental question is whether a genuine difference in reaction time that reflects a fundamental aspect of processing is obtained when bias toward either "same" or "different" judgments is minimized.

As documented by Krueger's (1978, Note 1; Krueger \& Shapiro, 1981a) survey of the relationship between error rate and reaction time in the "same-different" task, the error data clearly argue against a bias account of the advantage in "same" reaction time. Rather than the greater percentage of false-"same" responses (responding "same" to a "different" pair) predicted by a bias interpretation, false-"different" responses (responding "different" to a "same" pair) usually predominate with simultaneous presentation, whereas no clear pattern is evident with sequential presentation (Krueger \& Shapiro, 1981a).

The experiments reported by Ratcliff and Hacker

Requests for reprints may be sent to Robert W. Proctor, Department of Psychology, Auburn University, Auburn, Alabama 36849 .
(1981) to support a bias interpretation include one (Experiment 1) in which a direct manipulation of the relative criteria for "same" and "different" was employed and another (Experiment 2) in which the manipulation was accomplished indirectly by decreasing the discriminability between "same" and "different" pairs. Experiment 1 is of most importance because of the direct manipulation of criteria. In this experiment, subjects were tested in sessions in which they were asked to respond "same" only when sure (cautious "same" condition) and sessions in which they were to respond "different" only when sure (cautious "different" condition). The stimuli were pairs of four-letter strings that were either identical at all positions ("same") or differed at one to four positions ("different"). The primary finding emphasized by Ratcliff and Hacker was that although "same" judgments were faster than "different" judgments in the cautious "different" condition, the relationship was reversed in the cautious "same" condition. As a consequence of this reversal under biased conditions, Ratcliff and Hacker have concluded that the normally obtained "same-different" disparity is uninterpretable.

Perhaps the most interesting outcome of Ratcliff and Hacker's (1981) Experiment 1 is one they apparently overlooked. That outcome clearly argues against their conclusion that the reaction-time difference obtained under normal conditions cannot be interpreted as reflecting a genuine difference in processing. Specifically, although "different" judgments were faster than "same" judgments in the cautious "same" condition, the difference ("different," $515 \mathrm{msec}$; "same," $573 \mathrm{msec}$; difference, $58 \mathrm{msec}$ ) was $52 \mathrm{msec}$ less than the amount by which "same" judgments were faster than "different" judgments ("same," 472; "different," 582; difference, $110 \mathrm{msec}$ ) in the cautious " different" condition. This difference of $52 \mathrm{msec}$, which is within the general range of values usually obtained for the "same-different" disparity, clearly indicates that "same" pairs do have a benefit in rate of processing that is not attributable to bias factors. That is, the direct comparison of "same" and "different" reaction times within either the cautious "same" or cautious "different" condition is inappropriate because of the bias toward one of the two responses. The unbiased comparison in this instance involves the magnitude of the "same-different" disparity within each condition, and this comparison clearly shows the commonly obtained fast-"same" phenomenon.

In a similar experiment, by Krueger and Shapiro (1981b; Experiment 3), single-letter stimuli were employed and criteria were manipulated by varying the percentage of "same" and "different" pairs that 
occurred within blocks of trials $75 \%$ for one type of pair, $25 \%$ of the other). When "different" pairs predominated, "different" judgments were $17 \mathrm{msec}$ faster than "same" judgments. However, when "same" judgments predominated, they were $33 \mathrm{msec}$ faster than "different" judgments. Thus, although the specific values were less than those obtained by Ratcliff and Hacker (1981), the general pattern of results was identical. "Same" judgments showed an advantage in reaction time over "different" judgments.

Ratcliff and Hacker (1981) reported a second experiment in which they used another procedure to demonstrate that "same" judgments can be made to be slower than "different" judgments. In the common form of the multiletter matching experiment, "different" pairs are constructed by substituting one or more positions in one letter string with different letters to create the second string of the pair. Ratcliff and Hacker also included "different" pairs that were constructed by transposing two letters from one string to create the other member of the pair. Thus, in the transposed pairs, all of the letters were the same, but the positions of two were different. With the transposition pairs included as part of the experiment, "same" judgments were slower than "different" judgments to the substitution strings (as compared with which they are usually faster).

Ratcliff and Hacker (1981) focused on this change in the relationship between "same" and "different" judgments to substitution strings to support their claim that criterion changes influence the "samedifferent" disparity: However, this manipulation only indirectly causes a change in the criterion for "same" judgments, because the "different" pairs constructed by transposition are more difficult to discriminate from "same" pairs than are the "different" pairs constructed by substitution. Thus, "same" reaction time becomes primarily dependent on discriminating the "same" pairs from the transposed "different" pairs. The appropriate comparison to determine whether there is an advantage in the rate at which "same" pairs are processed would then seem to be between those pairs and the transposed "different" pairs. Although the high variability of reaction time as a function of the positions of the transposed letters and high error rates make the comparison tentative, "same" judgments are $46 \mathrm{msec}$ faster on the average than "different" judgments to the transposed pairs." The major point is that, al- though the relative difficulty of transposed "different" pairs has implications for models of multiletter matching (Ratcliff, 1981), the conclusion that their influence on "same" judgments invalidates the use of the "same-different" disparity in reaction time as a basis for models is unwarranted.

Clearly, criteria for responding can influence reaction-time differences. The critical issue is whether the fact that the magnitude and direction of reactiontime differences can be manipulated by biases renders the use of such differences obtained under relatively unbiased conditions unusable. Our contention is that it does not.

\section{REFERENCE NOTE}

1. Krueger, L. E. A theory of perceptual matching (Tech. Rep. 1). Columbus: Ohio State University, Human Performance Center, June 1977.

\section{REFERENCES}

Krueger, L. E. A theory of perceptual matching. Psychological Review, 1978, 85, 278-304.

Krueger, L. E., \& Shapiro, R. G. A reformulation of Proctor's unified theory for matching-task phenomena. Psychological Review, 1981, 88, 573-581. (a)

Krueger, L. E., \& Shapiro, R. G. Intertrial effects of samedifferent judgments. Quarterly Journal of Experimental Psychology, 1981, 33A, 241-265. (b)

Pachella, R. G. The interpretation of reaction time in information-processing research. In B. H. Kantowitz (Ed.), Human information processing: Tutorials in performance and cognition. Hillsdale, N.J: Erlbaum, 1974.

Proctor, R. W. A unified theory for matching-task phenomena. Psychological Review, 1981, 88, 291-326.

RATCLIFF, R. A theory of order relations in perceptual matching. Psychological Review, 1981, 88, 552-572.

RATClifF, R., \& HACKER, M. J. Speed and accuracy of same and different responses in perceptual matching. Perception \& Psychophysics, 1981, 30, 303-307.

TAYLOR, D. A. Effect of identity in the multiletter matching task. Journal of Experimental Psychology: Human Perception and Performance, 1976, 2, 417-428.

\section{NOTE}

1. Ratcliff (1981) reported a similar experiment, which did not show the advantage for "same" reaction time. However, in that experiment only one-third of the pairs were "same," as compared with $50 \%$ in Ratcliff and Hacker (1981), resulting in a bias toward "different" responses.

(Manuscript received January 25, 1982; accepted for publication January 27,1982 .) 